\title{
Design and deployment of semiochemical traps for capturing Anthonomus rubi Herbst (Coleoptera: Curculionidae) and Lygus rugulipennis Poppius (Hetereoptera: Miridae) in soft fruit crops
}

\author{
Michelle T. Fountain ${ }^{a}{ }^{*}$, Catherine Baroffio ${ }^{d}$, Anna-Karin Borg-Karlson ${ }^{\mathrm{g}}$, Phil Brain ${ }^{\mathrm{a}}$, \\ Jerry V. Cross ${ }^{\text {a }}$, Dudley I. Farman ${ }^{\text {h }}$, David R. Hall ${ }^{\text {h }}$, Baiba Ralle ${ }^{\mathrm{e}}$, Paulo Rendina ${ }^{\mathrm{b}}$, \\ Pauline Richoz ${ }^{d}$, Lene Sigsgaard ${ }^{\mathrm{f}}$, Sverre Storberget ${ }^{\mathrm{c}}$, Nina Trandem ${ }^{\mathrm{b}, \mathrm{c}}$, Atle Wibe ${ }^{\mathrm{i}}$ \\ ${ }^{a}$ NIAB EMR, New Road, East Malling, Kent, ME19 6BJ, UK \\ ${ }^{\mathrm{b}}$ Norwegian Institute of Bioeconomy Research (NIBIO), P.O. Box 115, NO-1431 Ås, Norway \\ ${ }^{c}$ Department of Ecology and Natural Resource Management, Norwegian University of Life Sciences, P.O. Box 5003, NO-1432 Ås, Norway \\ d Agroscope IPS, Research Center Conthey, Route des Eterpys 18, 1964 Conthey, Switzerland \\ e Latvian Plant Protection Research Centre, Struktoru iela 14a, Riga, LV, 1039, Latvia \\ ${ }^{\mathrm{f}}$ University of Copenhagen, Department of Plant and Environmental Sciences, Thorvaldsensvej 40, DK-1871 Frederiksberg C, Denmark \\ ${ }^{g}$ KTH Royal Institute of Technology, Department of Chemistry, 10044 Stockholm, Sweden \\ ${ }^{\mathrm{h}}$ Natural Resources Institute, University of Greenwich, Central Avenue, Chatham Maritime, Kent, ME4 4TB, UK \\ ${ }^{\mathrm{i}}$ NORSØK Norwegian Centre for Organic Agriculture, Gunnars vei 6, NO-6630 Tingvoll, Norway
}

\section{A R T I C L E I N F O}

\section{Article history:}

Received 8 August 2016

Received in revised form 28 April 2017

Accepted 2 May 2017

Available online 6 May 2017

\section{Keywords:}

Apoidea

Bycatch

Monitoring

Mass trapping

Pheromone

Plant volatiles

\begin{abstract}
A B S T R A C T
Strawberry blossom weevil (SBW), Anthonomus rubi Herbst (Coleoptera: Curculionidae) and European tarnished plant bug (ETB), Lygus rugulipennis Poppius (Hetereoptera: Miridae), cause significant damage to strawberry and raspberry crops. Using the SBW aggregation pheromone and ETB sex pheromone we optimized and tested a single trap for both species. A series of field experiments in crops and seminatural habitats in five European countries tested capture of the target pests and the ability to avoid captures of beneficial arthropods. A Unitrap containing a trapping agent of water and detergent and with a cross vane was more efficient at capturing both species compared to traps which incorporated glue as a trapping agent. Adding a green cross vane deterred attraction of non-pest species such as bees, but did not compromise catches of the target pests. The trap caught higher numbers of ETB and SBW if deployed at ground level and although a cross vane was not important for catches of ETB it was needed for significant captures of SBW. The potential for mass trapping SBW and ETB simultaneously in soft fruit crops is discussed including potential improvements to make this more effective and economic to deploy.
\end{abstract}

() 2017 Elsevier Ltd. All rights reserved.

\section{Introduction}

Across Europe, strawberry blossom weevil (SBW), Anthonomus rubi Herbst (Coleoptera: Curculionidae) and European tarnished plant bug (ETB), Lygus rugulipennis Poppius (Hetereoptera: Miridae) are serious pests in strawberry and some cane fruits causing economic loss for farmers. SBW females lay eggs in flower buds and then partially sever the peduncles. Damaged buds do not develop further resulting in a loss of yield (Aasen and Trandem, 2006; Jay et al., 2008). ETB pierces and feeds on flowers and developing

\footnotetext{
* Corresponding author.

E-mail address: Michelle.fountain@emr.ac.uk (M.T. Fountain).
}

fruitlets, causing fruit distortion and considerably decreasing fruit quality for market, up to 80\% distorted fruits (Cross et al., 2011; Fitzgerald and Jay, 2011).

Foliar applications of insecticides are the main method of controlling these pests. The loss of active compounds through the pesticides approval process, the evolution of pesticide resistance in many pest populations (e.g. in SWB, Aasen and Trandem, 2006), the need for selective control measures to prevent disruption of integrated pest management (IPM) practices (Hillocks, 2012, 2013) and high losses in organic production all require better timed and targeted control applications and alternative control methods for key pest species. In addition, the incidence of pesticide residues in fresh produce (European Food Safety Authority, 2015) and harm to 
beneficial insects (e.g. Croft and Brown, 1975; Cressey, 2015) are all justifications for alternative approaches to pesticide use (Hillocks, 2012, 2013).

In the EU, users of pesticides are required by law to monitor pests when possible, and only apply pesticides when pests are present in damaging numbers and other measures have failed, taking the resistance risk into account (Sustainable Use Directive, $2009 / 128 / E C$ ). The use of pheromone traps for monitoring insect pests is widespread in Europe and other main fruit growing regions of the world (Walton et al., 2004; Teixeira et al., 2009; Haghani et al., 2016). Trap design, placement and attractants may all have an important role in pheromone trap effectiveness, depending on pest behaviour and finding the best combination of these factors will improve trap efficacy (Blackmer et al., 2008; Switzer et al., 2009; Singh et al., 2013; Renkema et al., 2014).

Effective monitoring traps also have the potential to control pests through mass trapping (Faccoli and Stergulc, 2008; Witzgall et al., 2010; Abbes et al., 2012; Mwatawala et al., 2015) aiming to reduce pest numbers, sufficiently, to reduce fruit damage. Mass trapping has been used in the long term management of many pests and has the potential to be exploited for commercial strawberry production by suppressing or even eradicating low-density, isolated pest populations (El-Sayed et al., 2006). The combination of mass trapping and releases of the predator Nesidiocoris tenuis (Reuter) resulted in a 50\% reduction in tomato fruit infestation by the tomato leaf miner, Tuta absoluta (Meyrick) (Lepidoptera: Gelechiidae), compared to conventional treatments (Abbes et al., 2012). Mass trapping often reduces populations of pests in crops (e.g. Mafra-Neto and Habib, 2003), but there are fewer studies demonstrating successful damage reduction. Examples of successful use of mass trapping against Coleoptera include the spruce bark beetle, Ips typographus (L.) (Faccoli and Stergulc, 2008), and the palm weevils Rhynchophorus palmarum (L.) (Oehlschlager et al., 2002) and $R$. ferrugineus (Olivier) (Dembilio and Jaques, 2015).

The male-produced aggregation pheromone of SBW was identified as a blend of Grandlure I, Grandlure II and lavandulol by Innocenzi et al. (2001), and further work was carried out to make the blend more cost-effective by Innocenzi et al. (2001) and Cross et al. (2006b). In addition, the effect of host plant volatiles on SBW was investigated. Bichão et al. (2005a,b) showed that some neurons on the antenna of $A$. rubi are narrowly tuned to a few structurally related sesquiterpenes, aromatics or monoterpenes. Adding these plant volatiles to the aggregation pheromone has the potential to increase the attractiveness to SBW (Cross et al., 2006b; Wibe et al., 2011, 2014). Currently a blend of SBW aggregation pheromone and one plant volatile, 1,4-dimethoxybenzene, is widely used for SBW monitoring (Wibe et al., 2011, 2014).

Three compounds have been identified as components of the ETB female sex pheromone (Innocenzi et al., 2004; Frati et al., 2009) and a blend of these was further optimised and tested in field trials (Innocenzi et al., 2004, 2005; Fountain et al., 2008, 2011; Cross et al., 2011) to develop an effective lure and trap for monitoring males (Fountain et al., 2014). In addition, some plant volatiles such as phenylacetaldehyde have been identified as attractants for female ETB (Frati et al., 2009; Fountain et al., 2010; Koczor et al., 2012).

For both target species, initial testing assessed different trap types and colours, most frequently using traps which incorporated sticky glue as the trapping agent (Innocenzi et al., 2001; Cross et al., 2006a, 2006b; Jay et al., 2008). These traps were not optimal for SBW as weevils were often found around the traps, but not in or on them (Cross et al., 2006a). Initial experiments for attracting ETB employed various sticky trap designs and colours but this was before the pheromone was widely available (Holopainen et al., 2001; Blackmer et al., 2008).
Changes in trap design leading to improved pest capture will make a monitoring trap more sensitive and mass trapping more effective. Traps must be competitive with the surrounding crop, ensure the pest is captured and not kill or disrupt significant numbers of natural enemies and other beneficial insects, e.g. pollinators. In addition, it should not become saturated with bycatch and it should be easy to use and maintain, and be cost effective.

To help reduce pesticide inputs, further development of the traps was necessary to a) improve target pest capture, b) combine traps for two common species in strawberry and c) develop a trap which was easy to maintain and economically viable for future mass trapping. Studies were carried out in Denmark, Latvia, Norway, Switzerland and the UK comparing the effect of various trap designs on captures of the target pests including non-target, beneficial, species.

\section{Materials and methods}

\subsection{Traps}

Two basic designs of trap were evaluated; delta traps $(20 \mathrm{~cm} \times 20 \mathrm{~cm})$ with white sticky inserts and green Unitraps consisting of a bucket with a funnelled entrance and green or white cross vanes between the bucket and the roof (bucket $16 \mathrm{~cm}$ dia, $12.5 \mathrm{~cm}$ high with $3 \mathrm{~cm}$ dia opening, cross vanes $10 \mathrm{~cm}$ high, cover $16.5 \mathrm{~cm}$ dia). The latter trap, from hereon in, will be referred to as Unitraps. Water $(250 \mathrm{ml})$ and a drop of detergent was added to the Unitraps as killing agent. Traps were purchased from Agrisense (Treforest, Pontypridd, UK), International Pheromone Systems Ltd. (The Wirral, Merseyside, UK) or Agralan (Swindon, UK).

\subsection{Lures}

For trapping ETB with live females, individual mature, virgin, female ETB from a laboratory culture were contained in a cage (hair roller $6 \mathrm{~cm} \times 3 \mathrm{~cm}$ with gauze around the outside and a lid at either end, holding the gauze in place). The cage contained a piece of damp paper and a section of bean as food and was anchored into the top of the trap under the roof. Female ETB were replaced weekly.

Lures for SBW were polyethylene sachets containing $100 \mu \mathrm{l}$ of 1:4:1 blend of Grandlure I: Grandlure II: lavandulol plus $200 \mathrm{mg}$ 1,4-dimethoxybenzene (Wibe et al., 2014) (International Pheromone Systems Ltd.). Lures for ETB were pipette tips containing $10 \mu \mathrm{g}$ hexyl butyrate, $0.3 \mu \mathrm{g}(E)$-2-hexenyl butyrate and $2 \mu \mathrm{g}(E)-4$ oxo-2-hexenal in $100 \mu \mathrm{l}$ sunflower oil (Fountain et al., 2014), prepared at the Natural Resources Institute. Lures were hung from the roof of delta traps or the cover of Unitraps.

\subsection{Comparison of delta traps and Unitraps for trapping ETB}

Two experiments were carried out in a weed field (Chenopodium and Matricaria) at NIAB EMR in the UK (Lat: 51.285494 north, Long: 0.461177 east) using virgin female ETB as bait (Table 1). In Experiment A (27 June - 11 July 2008), delta traps and Unitraps were compared with different materials for retaining the insects. The delta traps had either the standard wet glue inserts, dry glue inserts (Agrisense), wet glue inserts with additional sticker or wet glue inserts sprayed with cypermethrin $\left(0.0014 \mathrm{ml}\right.$ sticky base ${ }^{-1}$, equivalent to $0.35 \mathrm{~L} \mathrm{ha}^{-1}$ ). The Unitraps had white cross vanes or cross vanes constructed from white insect trapping cards impregnated with lambda-cyhalothrin. A clear delta trap was also tested, made of clear vinyl sheets held together at the top with a paper binder and with a white, wet, glue insert (Table 1 ).

In Experiment B (27 August - 1 September 2008), different 
Table 1

Comparison of traps for capturing male ETB using virgin female ETB as bait in UK.

\begin{tabular}{ll}
\hline Trap & Capture device \\
\hline Experiment A (27 June - 11 July 2008) & \\
Green delta & Wet glue sticky insert \\
Green delta & Dry glue sticky insert \\
Green delta & Wet glue sticky insert + cypermethrin \\
Green delta & Wet glue sticky insert + Oecotack \\
Unitrap (white cross vane) & Correx card + water with detergent \\
Unitrap (lambda-cyhalothrin white cross vane) & Water + detergent \\
Clear delta & Wet glue sticky insert \\
Experiment B (27 August - 1 September 2008) & \\
Green delta & Wet glue sticky insert + Oecotack \\
Clear delta & Wet glue sticky insert + Oecotack \\
Agrisense vane funneled (white cross vanes) & Water + detergent \\
Unitrap (green cross vanes) & Water + detergent \\
Unitrap (white cross vanes) & Water + detergent \\
Unitrap (yellow cross vanes) & Water + detergent \\
Sticky stake trap & Oecotack \\
\hline
\end{tabular}

coloured traps were compared. These were green delta traps, clear delta traps, and green Unitraps with white, green or yellow cross vanes. A sticky stake trap was also tested consisting of a wooden stake $(3 \times 3 \times 40 \mathrm{~cm})$ inserted in the ground and coated in Oecotack insect trapping glue (Agralan) above ground.

Delta traps were suspended on two bamboo canes $(50 \mathrm{~cm}$ above the ground) and Unitraps were dug into the ground to the level of the funnel. Four replicates of each trap in each experiment in a randomised block design were spaced $>10 \mathrm{~m}$ apart and the numbers of male ETB captured recorded weekly.

\subsection{Investigation of effects of grid on Unitraps for ETB to exclude capture of bees (Apoidea)}

The trial was set up in a weed field (Chenopodium and Matricaria) at NIAB EMR in 2009. Traps were Unitraps with a green or white cross vanes baited with ETB pheromone. The latter were tested with or without a black plastic grid $(4 \times 5 \mathrm{~mm}$ mesh $)$ fitted over the hole of the funnel since white is attractive to bees. Catches of ETB in these traps were compared with those in a green delta trap with a white sticky insert. There were 5 replicates of each treatment in a randomised block design and the traps were spaced $>10 \mathrm{~m}$ apart. Traps were in place from 11 May - 19 June and from 11 May - 18 August and catches were recorded either weekly or fortnightly.

\subsection{Effect of cross vane height on catches of ETB and SBW}

ETB trials were in the UK on the perimeter of a strawberry crop at NIAB EMR (15 July - 12 August 2013). SBW trials were in a strawberry crop in the north-west area of Norway, Møre and Romsdal County (Lat: 62.697778 north, Long: 7.385278 east) (2 July - 27 August 2013). Traps were baited with the corresponding synthetic pheromone lures.

For the ETB trial, Unitraps had either no cross vane (lid attached directly to bucket), a normal size cross vane (10 cm high), or the cross vane area was doubled by joining up two cross vanes with a $1 \mathrm{ml}$ pipette tip on each corner to secure the vanes $(20 \mathrm{~cm}$ high). For the SBW test, Unitraps had either no cross vane, a standard height $(10 \mathrm{~cm})$ cross vane or a vane which was half the height $(5 \mathrm{~cm})$. All cross vanes were green and the traps stood on the ground and held in place with a wire hoop.

There were 10 replicates of each treatment arranged in a randomised complete block design. Plots were rows with single traps deployed spaced $10 \mathrm{~m}$ apart for ETB and $20 \mathrm{~m}$ apart for SBW. Counts of SBW and male ETB were made weekly.

\subsection{Comparison of trap designs for trapping of SBW and ETB}

Ten different trap designs were compared to find one effective trap for both SBW and ETB. Experiments were carried out in the UK and Latvia on two occasions, one to coincide with SBW emergence (UK 19 March - 05 July 2012; Latvia 17 May - 19 July 2012) and the second with the ETB main flight period (UK 23-31 July 2012; Latvia 30 July - 31 August 2012).

In the UK, organic strawberry plantations in Hereford (Lat: 52.050051 north, Long: 2.491226 west) were utilised for the SBW experiment and a strawberry crop at NIAB EMR for the ETB test. In Latvia the SBW trial was set up in organic strawberry plantations (Lat: 57.113804 north, Long: 24.530401 east; Lat: 56.807688 north, Long: 24.271681 east; Lat: 56.630664 north, Long: 23.344844 east; Lat: 56.595720 north, Long: 23.272959 east; Lat: 56.921632 north, Long: 23.211209 east) and the ETB trial in a sowing of Medicago sativa L. near Vecauce (Lat: 56.595720 north, Long: 23.27295 east).

Trap designs tested are shown in Table 2 and were baited with the synthetic SBW or ETB lures according to the target pest. Traps included Unitraps with different coloured cross vanes, with and without excluders. The effect of attaching the lure inside the bucket rather than to the top of the cross vanes was tested. Traps made of a vertical cylinder of card $(25 \mathrm{~cm} \times 10 \mathrm{~cm}$ dia) coated with dry glue in different colours were tested as these are supplied commercially for ETB (Agralan), as were the Xlure-RTU sticky trap $(12 \mathrm{~cm} \times 3 \mathrm{~cm})$ from Russell IPM. Two simple, homemade traps were tested: the sticky stake trap and a white plastic strip $(45 \times 150 \times 3 \mathrm{~mm})$ in $45 \mathrm{~mm}$ pot containing water $+0.1 \%$ Triton X100.

The two experiments (one in the UK and one in Latvia) were set up as a randomised complete block design. There were five replicates of each treatment in each experiment. Because of the area needed for each replicate, experiments were conducted across several plantations, with each considered a replicate with all 10 treatments. Traps were deployed 15-20 m apart along the edges of the fields. The traps were stood on the ground, with foliage around them removed. Sticky traps were set with their bottom edge touching the ground. Unitraps were held in place with a wire hoop and contained water plus a drop of detergent.

Total counts of SBW and male ETB in each trap were made every 2 weeks. Bycatch of other notable insects were recorded into broad taxa and included honeybees, bumblebees, solitary bees and Diptera ( $>2 \mathrm{~mm})$.

\subsection{Effect of trap height and habitat on catches of ETB and SBW}

The ETB trial was set up in a strawberry plantation (cv. 'Finesse') 
Table 2

Trap designs tested for trapping SBW and ETB in the UK and Latvia. Traps were baited with synthetic SBW or ETB lures.

\begin{tabular}{|c|c|c|c|}
\hline Trap design & Killing agent & Position of lure & Source of trap \\
\hline Unitrap: White cross vane with excluder-grid $(4 \times 5 \mathrm{~mm})$ & Water $+0.1 \%$ Triton X100 & Top of cross vane & Agralan \\
\hline Unitrap: White cross vane with excluder-grid ( $4 \times 5 \mathrm{~mm})$ & Water $+0.1 \%$ Triton $\mathrm{X} 100$ & Inside bucket attached to funnel & Agralan \\
\hline Unitrap: White cross vane without excluder-grid & Water $+0.1 \%$ Triton X100 & Top of cross vane & Agralan \\
\hline Unitrap: Green cross vane without excluder-grid & Water $+0.1 \%$ Triton $\mathrm{X} 100$ & Top of cross vane & Agralan \\
\hline Sticky stake trap $(2.5 \times 2.5 \times 50 \mathrm{~cm})$ & Oecotack wet glue & Top of stake & NIAB EMR \\
\hline Yellow card cylinder $(25 \times 10 \mathrm{~cm})$ & Coated in wet glue & Top of cylinder & Agralan \\
\hline Blue card cylinder $(25 \times 10 \mathrm{~cm})$ & Coated in dry glue & Top of cylinder & Agralan \\
\hline Yellow card cylinder $(25 \times 10 \mathrm{~cm})$ & Coated in dry glue & Top of cylinder & Agralan \\
\hline White plastic strip $(45 \times 150 \times 3 \mathrm{~mm})$ in $45 \mathrm{~mm}$ pot & Water $+0.1 \%$ Triton X100 & Top of strip & NIAB EMR \\
\hline Xlure R.T.U floor trap & Oecotack sticky insert inside & Inside, in middle on base & Russell \\
\hline
\end{tabular}

at NIAB EMR (14 August - 26 September 2011). Treatments were green cross vane Unitraps with water and detergent as a trapping agent. Traps were wired in position at ground level $(0 \mathrm{~m})$ or onto the bracing bar of the tunnel ( $1.25 \mathrm{~m}$ from the ground) or onto the centre top ridge pole of tunnel ( $4 \mathrm{~m}$ from the ground). Traps were baited with the synthetic ETB sex pheromone lure. The trial had a randomised complete block design with 5 replicates and the traps were arranged around the edge of the plantation $>10 \mathrm{~m}$ apart. Trap catches were recorded weekly.

The SBW trials were carried out in raspberry in 2012 at three locations in Denmark, Norway and Switzerland (Table 3). Three habitat types were tested; the crop (raspberry), the boundary of the crop and $50 \mathrm{~m}$ into the adjacent forest. Traps were green Unitraps with a white cross vane with a synthetic SBW lure, a pollinator exclusion grid across the funnel opening, and water with detergent as the trapping agent in the bucket. Traps were mounted on poles at three heights above ground level $(0 \mathrm{~m}, 0.5 \mathrm{~m}$ and $1.5 \mathrm{~m})$. There were 9 replicates in Denmark and Norway and 12 in Switzerland. Traps in each habitat were $>3 \mathrm{~m}$ apart and catches recorded every 7-14 days.

\subsection{Data analysis}

All analyses were carried out using Genstat v 14 (VSN International, 2011). Mean total catches during the experiments were square root transformed, to stabilise the variances, and subjected to analysis of variance (ANOVA). Where significant differences between means were indicated, means were separated by Least Significant Difference (LSD) test with $P<0.05$. For the majority of the UK experiments the datasets were analysed by ANOVA in which the treatment factors were either trap design, cross vane height, trap height etc., with random effects as blocks in the randomised experiment designs.

Initially all of the Latvia and UK trap type data were combined, square root transformed and analysed using ANOVA. Treatment factors were trap type and country and random effects were blocks nested within country and treatments nested within blocks. To further analyse the same data on a multiplicative scale, accounting for different population densities between the two countries, we then used a Generalised Linear Mixed Model (GLMM) (Breslow and Clayton, 1993) with the Poisson distribution and a log-link. This was analysed with the same treatment factors and the same random effect model as the ANOVA, above.

When analysing the effect of trap height on catches of SBW catches, mean counts over the trapping season for countries (Norway, Denmark, Switzerland) were analysed using ANOVA with trap height, habitat and country as fixed effects and replicates within country, and height within blocks as random effects.

\section{Results}

\subsection{Comparison of delta traps and Unitraps for trapping ETB}

In Experiment $\mathrm{A}$, catches of ETB were low and there were no significant differences between the trap types tested $\left(\mathrm{F}_{6,18}=1.22\right.$, $P=0.343$; data not shown). The addition of lambda-cyhalothrin or cypermethrin to the traps did not significantly improve ETB catches.

In Experiment B, there were significantly more male ETB captured in the green cross vane Unitrap compared to the green or clear delta traps $\left(\mathrm{F}_{6,18}=2.16, P=0.096\right.$, $1 \mathrm{sd}=2.768$, Fig. 1$)$. Unitraps with white or yellow cross vanes had intermediate trap catches.

\subsection{Investigation of effects of a grid on Unitraps for ETB to exclude capture of bees (Apoidea)}

Using a plastic grid over the hole of the funnel in the white cross vane Unitraps significantly reduced the numbers of captured bumblebees $\left(\mathrm{F}_{4,16}=6.25, P=0.003\right.$, lsd $=0.837$, Fig. 2$)$ and honeybees $\left(\mathrm{F}_{4,16}=60.44, P<0.001\right.$, lsd $=0.756$, Fig. 2$)$. Although the white cross vane Unitraps had fewer ETB if a grid was placed over the funnel hole, this was not significant. The main differences were that the green cross vane Unitrap without a grid captured significantly more male ETB than the green Unitrap with a grid or a green delta trap with a sticky glue insert $\left(\mathrm{F}_{4,16}=7.24, P=0.002\right.$, lsd $=1.248$, Fig. 2). These results suggested that a grid is not needed

Table 3

Location and age of raspberry plantations used for testing the effect of trap height on catches of SBW (CH Switzerland, NO Norway, DK Denmark).

\begin{tabular}{|c|c|c|c|c|}
\hline Country & Location & Coordinates Latitude north, Longitude east & Production type & Plantation year \\
\hline $\mathrm{CH}$ & Bruson, Valais & 46.0037, 7.3191 & Open & 2005 \\
\hline $\mathrm{CH}$ & Nendaz, Valais & $46.1834,7.2942$ & Open & 2005 \\
\hline $\mathrm{CH}$ & St Sébastien, Valais & $46.198,7.31306$ & Open & 2004 \\
\hline NO & Skåla, Molde & $62.6953,07.3769$ & Protected & 2010 \\
\hline NO & Skjønsby & $60.8278,10.7970$ & Open & 2008 \\
\hline NO & Torp & $59.6677,10.6912$ & Open & 2010 \\
\hline DK & Gyrstinge & $55.4770,11.6830$ & Open & 2010 \\
\hline DK & Eggeslevmagle & $55.2843,11.3300$ & Protected & 2010 \\
\hline DK & Kildebrønde & $55.6033,12.2650$ & Protected & 2010 \\
\hline
\end{tabular}




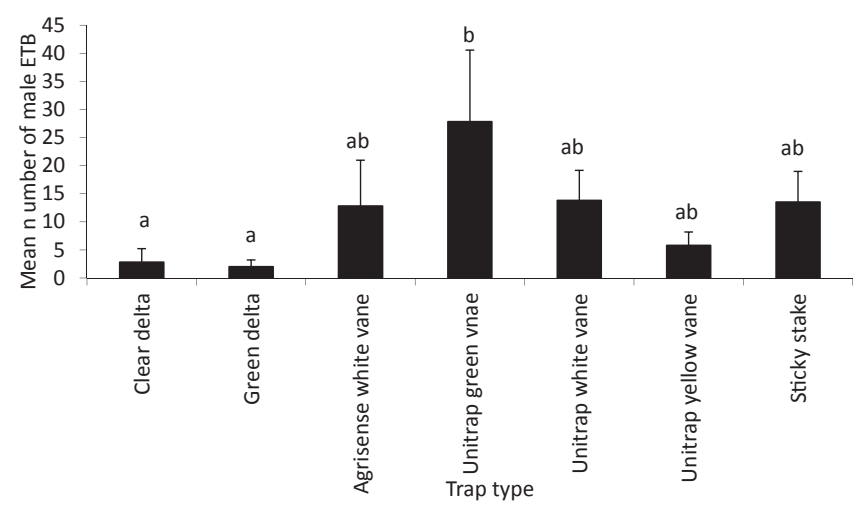

Fig. 1. Mean numbers $( \pm$ S.E.) of male ETB captured in different traps (Table 1 ) baited with live female ETB in the UK (27 Aug - 1 Sept 2008; means with the same letter are not significantly different, $P>0.05$ ).

if a green cross vane is used in the Unitraps. Green cross vanes reduced the bycatch whilst maintaining a significant catch of male ETB.

\subsection{Effect of cross vane height on catches of ETB and SBW}

In the UK trial, the height of the green cross vane had no effect on the numbers of male ETB trapped in the Unitraps. There was also no effect on bumblebee $\left(F_{2,18}=1.19, P=0.328\right.$, lsd $\left.=0.380\right)$, carabid $\left(\mathrm{F}_{2,18}=0.08, P=0.924\right.$, lsd $\left.=0.876\right)$, spider $\left(\mathrm{F}_{2,18}=0.78, P=0.474\right.$, lsd $=0.716)$, earwig $\left(F_{2,18}=1.47, P=0.257\right.$, lsd $\left.=0.689\right)$, large Diptera $\left(F_{2,18}=0.92, P=0.417\right.$, lsd $\left.=0.845\right)$ or ant numbers $\left(F_{2,18}=0.10, P=0.908\right.$, lsd $\left.=0.695\right)$. However, in general, captures of some notable groups of invertebrates did increase as the vane height was increased, including the mirid Calocoris norvegicus (Gmelin) $\left(F_{2,18}=11.12, P<0.001\right.$, lsd $\left.=0.729\right)$, slugs $\left(F_{2,18}=3.58\right.$, $P=0.049$, lsd $=1.010)$, Coccinellidae $\left(F_{2,18}=5.68, P=0.012\right.$, lsd $=0.801)$ and Opilione $\left(F_{2,18}=9.04, P=0.002\right.$, lsd $=0.718$, Fig. 3$)$.

In the trial in Norway, SBW catches were significantly lower in the half height $(5 \mathrm{~cm})$ cross vane Unitraps compared to the full height cross vane traps $\left(F_{2,18}=5.21, P=0.016\right.$, lsd $=0.681$, Fig. 4$)$. When the cross vane was removed altogether, intermediate numbers of SBW were captured.

\subsection{Comparison of trap designs for trapping of SBW and ETB}

While the ANOVA gave significant trap type $\times$ country interactions for most variables, this was not the case in the GLMM

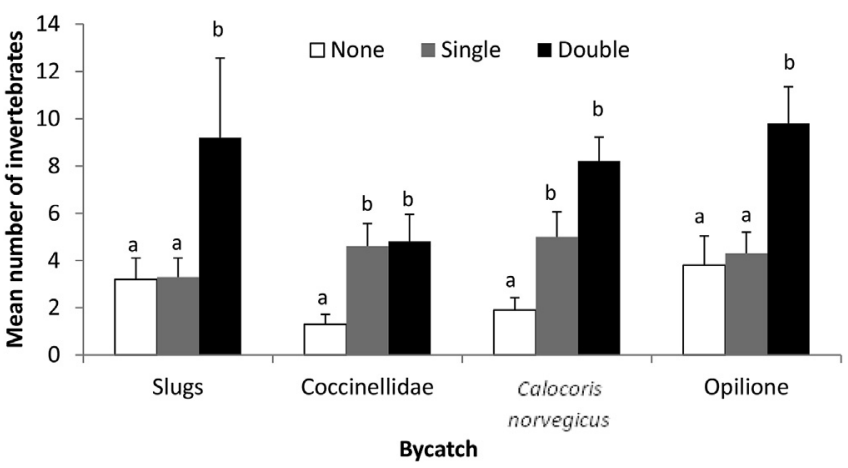

Fig. 3. Mean numbers ( \pm S.E.) of invertebrate bycatch captured in green Unitraps with either no cross vane, a single height $(10 \mathrm{~cm})$ or double height $(20 \mathrm{~cm})$ green cross vane (UK, 15 July - 12 August 2013; means with different letters for each invertebrate group are significantly different, $P<0.05$ ).

analyses for any of the variables. For the SBW and ETB experiments, there was no significant trap type $\times$ country interaction in the GLMM analysis for SBW counts, ETB counts, or any of the bycatches (not reported), but there were significant differences between the trap types. This lack of interaction in the GLMM implies the trap means differed between the two countries by a constant ratio irrespective of trap type. To preserve conformity with other analyses and for simplicity, only results from ANOVA are presented (Figs. 5 and 6). Numbers of SBW captured in the Unitraps with white or green cross vanes, even with the excluder grid $\left(\mathrm{F}_{9,72}=13.42, P<0.001\right.$, lsd $=0.889$, Fig. $\left.5 \mathrm{~A}\right)$, were significantly

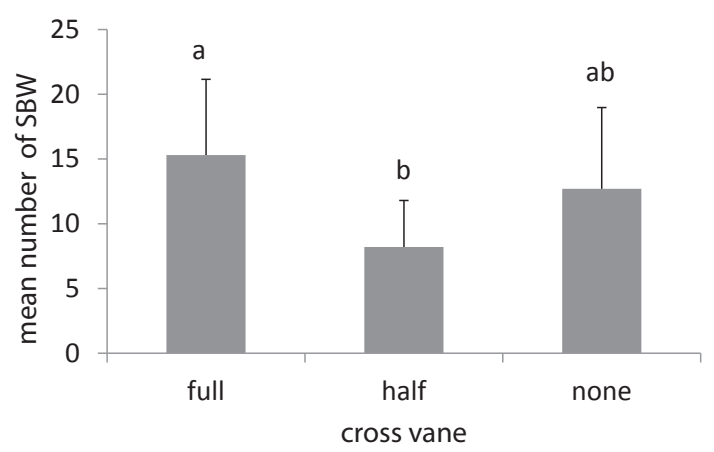

Fig. 4. Mean numbers $( \pm$ S.E.) of SBW captured in green Unitraps with either no cross vane, a full height $(10 \mathrm{~cm})$ or half height $(5 \mathrm{~cm})$ white cross vane (Norway, 16 July -27 August 2013; means with different letters are significantly different, $P<0.05$ ).

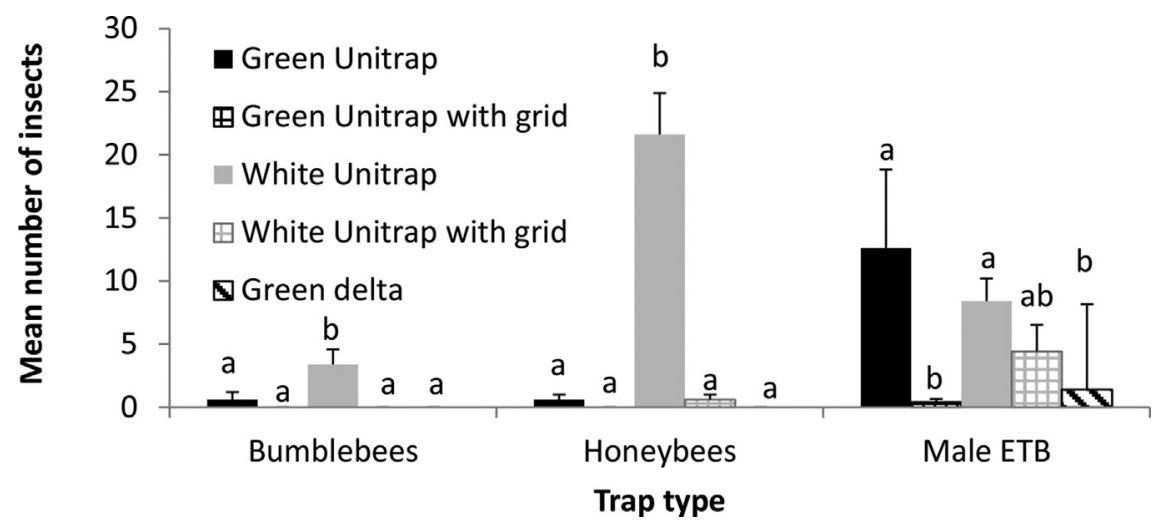

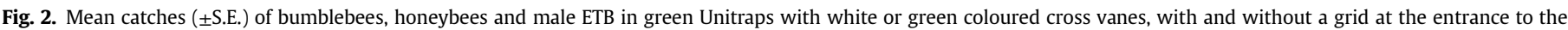
funnel in comparison to a green Delta trap (UK, 11 May - 19 June and 11 May - 18 August; means with different letters for each species are significantly different, $P<0.05$ ). 

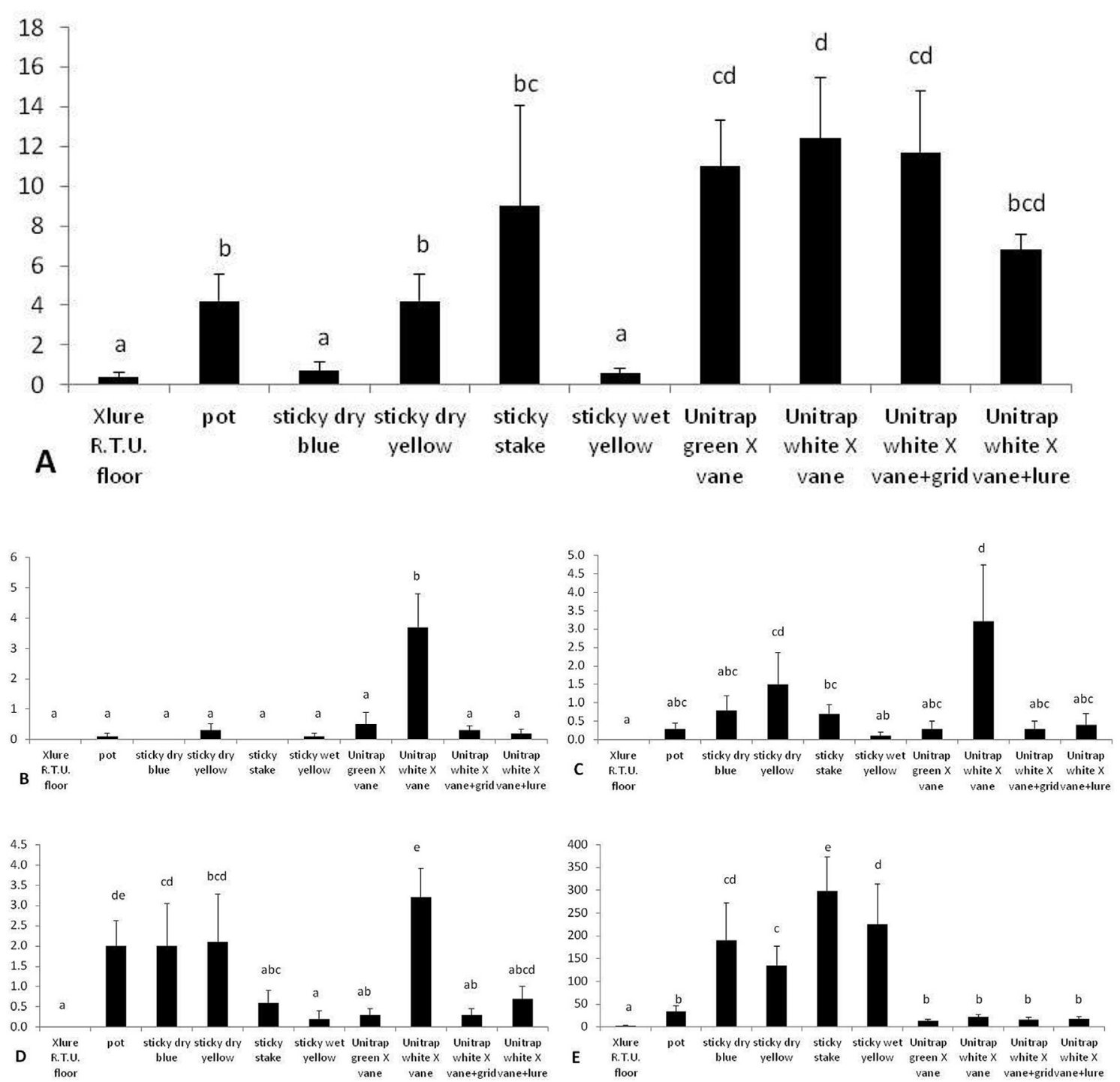

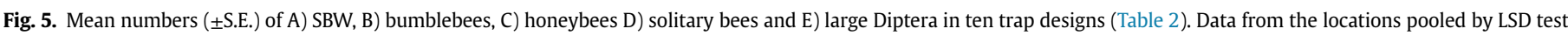

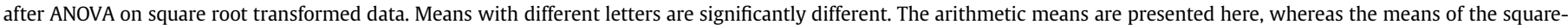
root transformed counts are grouped, hence there may be apparent discrepancies in the groupings.

higher than in most other trap types (see Table 2). The lure placed inside the bucket of the Unitrap, instead of under the lid, did not significantly improve the capture of SBW in the Unitraps (Fig. 5A).

By-catch was also affected by trap design. Higher numbers of bumblebees, in particular, were captured in the Unitraps with the white cross vanes and no excluder grid compared to all other traps $\left(\mathrm{F}_{9,72}=10.74, P<0.001\right.$, lsd $=0.418$, Fig. 5B $)$. Honeybees $\left(\mathrm{F}_{9,72}=2.83, P=0.007\right.$, lsd $=0583$, Fig. $\left.5 \mathrm{C}\right)$ and solitary bees $\left(F_{9,72}=5.15, P<0.001\right.$, lsd $=0.632$, Fig. 5D) were also more likely to be captured in Unitraps with white cross vanes and no excluder grid than other Unitraps. However, significantly more solitary bees were also captured in the pot trap and blue and yellow dry sticky glue traps than, for example, the Xlure R.T.U. floor trap and the yellow wet glue sticky trap.

Large Diptera ( $>2 \mathrm{~mm}$ ) were more abundant on traps which had glue as the trapping agent in comparison to liquid based traps and the Xlure R.T.U floor trap $\left(\mathrm{F}_{9,72}=52.12, P<0.001\right.$, lsd $=1.986$, Fig. 5E).

Later in the season, in the ETB trial, more ETB were captured in green or white cross vane Unitraps without the excluder grid compared to other trap types, although small numbers were captured in the pot trap and in the Unitrap with the excluder grid $\left(\mathrm{F}_{9,72}=33.76, P<0.001\right.$, lsd $=1.414$, Fig. $\left.6 \mathrm{~A}\right)$. Placing the pheromone lure inside the bucket of the Unitrap did not increase catches of ETB (Fig. 6A).

By-catch, later in the season, included honeybees and large Diptera. Honeybees were more likely to be captured in the Unitraps with the white cross vane and without the $4 \times 5 \mathrm{~mm}$ excluder grid; small but significant numbers of honeybees were also captured on the blue sticky card $\left(F_{9,72}=3.57, P=0.001\right.$, lsd $=0.598$, Fig. $\left.6 \mathrm{~B}\right)$. As with the previous study, earlier in the season, by-catches of large Diptera ( $>2 \mathrm{~mm}$ ) in the ETB experiment were higher on traps which comprised sticky glue, including the yellow wet and dry cards, the blue card and the sticky stake trap, in comparison to traps which used a liquid as the method of capture $\left(\mathrm{F}_{9,72}=50.09, P<0.001\right.$, lsd $=1.333$, Fig. 6C).

\subsection{Effect of trap height and habitat on catches of ETB and SBW}

In the UK experiment, there were significantly more male ETB 

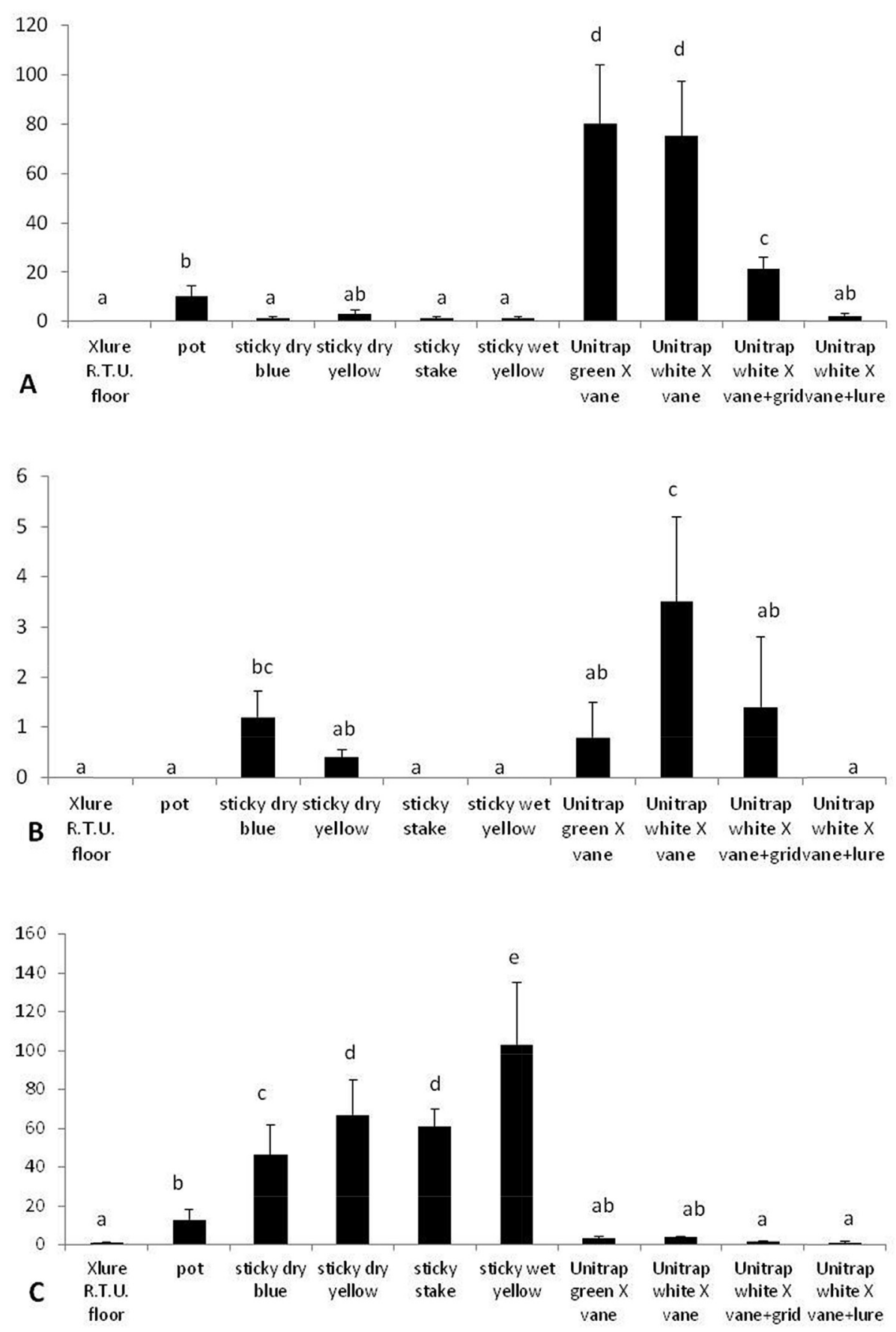

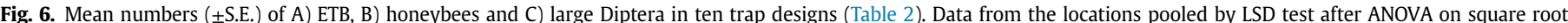

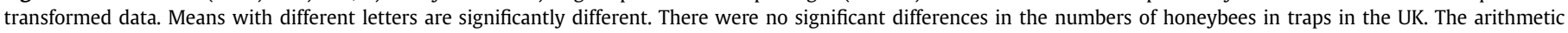
means are presented here, whereas the means of the square-root transformed counts are grouped hence there may be some discrepancies in the groupings.

caught in traps placed on the ground within the strawberry row (mean 22.2) than in the traps wired to the tunnel bracing bar $1.25 \mathrm{~m}$ above ground (mean 1.0) or the ridge pole $4 \mathrm{~m}$ above ground (mean $0.2)\left(F_{2,8}=29.13, P<0.001\right.$, lsd $=1.558$, data not shown $)$.

There were significant interactions between country and habitat $\left(F_{4,14}=10.61, P<0.001\right.$, lsd $\left.=0.55\right)$, and habitat and trap height $\left(F_{4,42}=3.13, P=0.024\right.$, lsd $\left.=0.257\right)$. There were no other significant interactions. The numbers of SBW captured in Denmark and Switzerland were lower than those in Norway, particularly in raspberry crops and the crop boundary compared to the forest (Fig. 7A). In the boundary and the crop, SBW was more likely to be trapped at $0 \mathrm{~m}$ compared to 0.5 or $1.5 \mathrm{~m}$ (Fig. 7B).

\section{Discussion}

In this study we developed and tested traps for SBW and ETB monitoring. The best trap, effectively capturing both species with minimal bycatch, was the green cross vane Unitrap with no excluder grid over the hole to the funnel (Fig. 8). This trap gave best capture of the two pest species if deployed on the ground. The white cross vanes previously used to trap SBW (Cross et al., 2006a,b; Wibe et al., 2014) did not improve capture compared to 

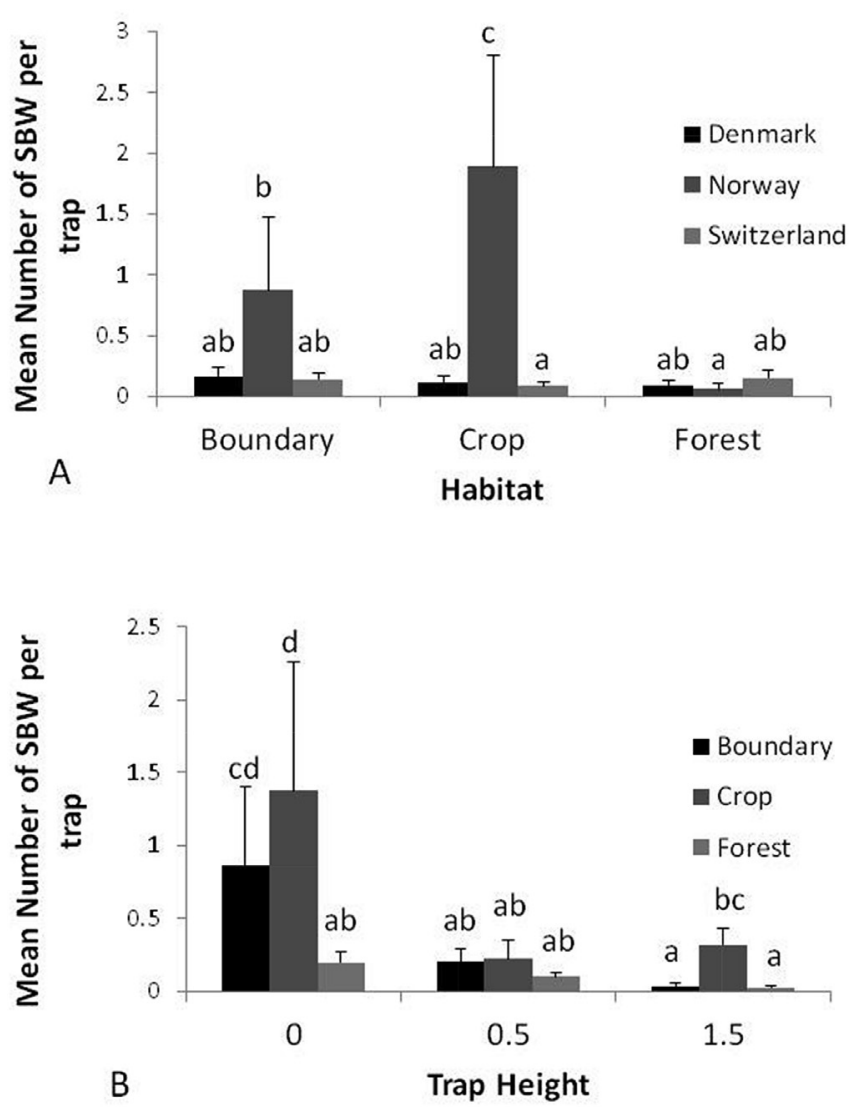

Fig. 7. Mean number $({ }$ S.E. $)$ of SBW per trap in A) the boundary, crop (raspberry) or forest in the 3 countries (Denmark, Norway and Switzerland) and B) at different heights $(0,0.5$ and $1.5 \mathrm{~m})$ in the 3 habitat types (boundary, crop and forest). Data from 9 (Denmark and Norway) or 12 locations (Switzerland) locations in 3 countries pooled by LSD test after ANOVA on square root transformed data. Means with different letters are significantly different.

green cross vanes and more bees were attracted. Bees could be excluded by use of a plastic mesh grid over the Unitrap funnel entrance, but this impeded the capture of ETB. Water and detergent were better for trapping ETB than glue, and ETB and SBW have been observed to free themselves from glue traps (pers. obs.). Overall the sticky traps were unsuitable for trapping SBW and ETB because they became contaminated and potentially saturated with other arthropods.

The height of the Unitrap cross vanes did not affect the capture of ETB, but the $10 \mathrm{~cm}$ cross vanes were most effective for capture of SBW. However, an increase in cross vane height did increase the capture of some beneficial arthropods including Coccinellidae and Opilione. Trap contaminants, in particular slugs, seemed to increase with vane height and hence the management of slugs through irrigation control and crop management is needed. In addition, the height which the trap is placed affected trapping efficacy. The ETB traps placed near to the ground at crop height captured more males than traps placed higher in the tunnel structure. Likewise, SBW was more likely, in Norway, to be captured on the ground in the forest. This may be because the wild fruits are closer to the ground compared to commercially grown fruits which are tied vertically into post and wire systems with the fruit higher than would be natural.

Although this trapping system is cost effective for monitoring, further improvements and reduction in cost need to be made for mass trapping. An attempt was made to find a low cost, small, trap that could be deployed in large numbers for mass trapping.

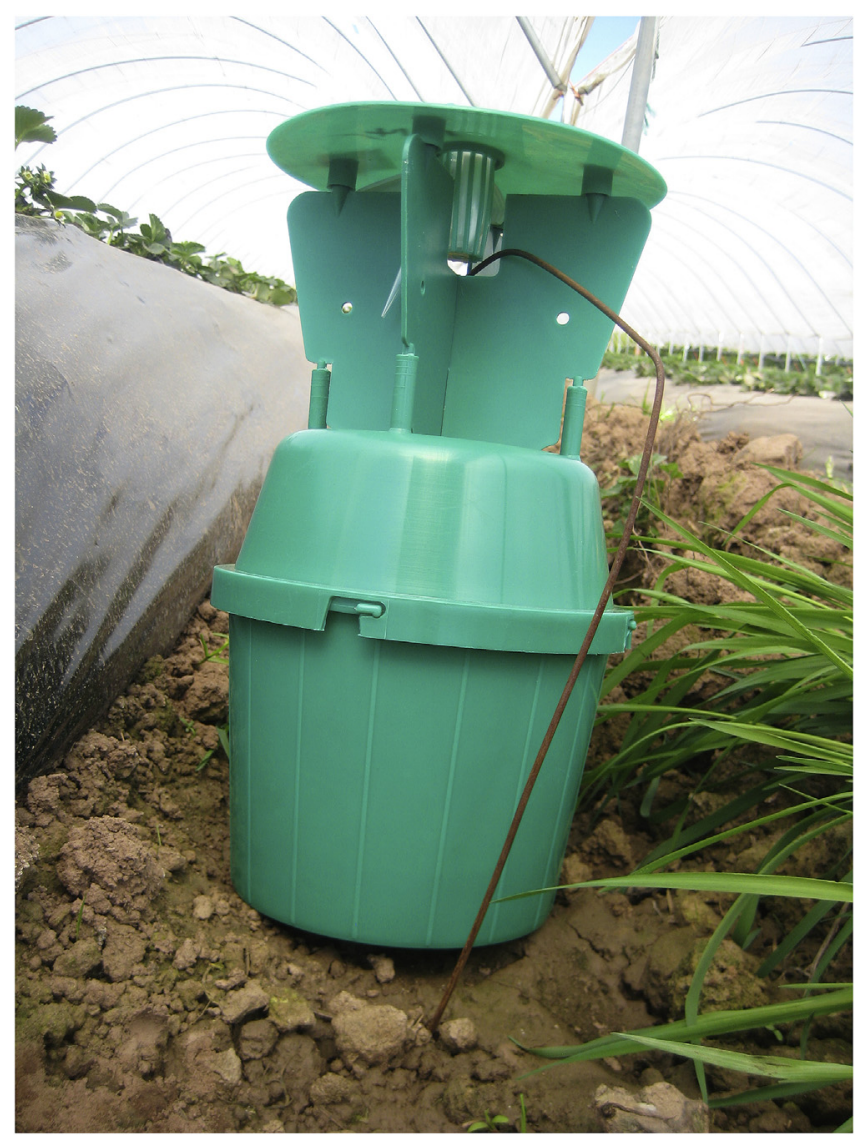

Fig. 8. Green cross vane Unitrap anchored into place on the ground in a strawberry crop. The pheromone dispensers are deployed in the cage inserted into the lid. (For interpretation of the references to colour in this figure legend, the reader is referred to the web version of this article.)

However, none of the traps, including prototypes, were as affective as the Unitrap with green cross vanes (Fig. 8).

An obvious flaw in the trap system tested here is the lack of an attractant for female ETB. However, phenylacetaldehyde and/or (E)cinnamaldehyde (Koczor et al., 2012) could be added to the sex pheromone to increase catches of female ETB. An alternative method to the drowning solution, which needs to be emptied and topped up on a monthly basis, would make the trap easier to maintain. There is the potential to incorporate an insecticide (Navarro-Llopis et al., 2015) or biological control agent onto the inside of the trap. This would be a lure and kill system where the insect would enter and then die either inside the trap or after leaving.

In addition, the lures also need maintenance. SBW lures last at least two months under field conditions (Cross et al., 2006a), but the longevity of the ETB lures is approximately four weeks (Fountain et al., 2014). It would be beneficial to increase the longevity of these lures and/or improve the deployment and replacement of lures in the traps. Finally, the traps were often placed in the leg row of the strawberry crop to avoid disturbance by spray machinery and fruit pickers, but this made them difficult to access on a regular basis (see Fig. 8).

In this study we did not test lures for both species in the trap at the same time. Further studies are required to ensure that the components of the two lures remain attractive to the pest species when placed together. It is considered unlikely there would be any interaction in view of the very different chemical structures of the pheromone components. A combined trap would save time in 
monitoring and push the cost-benefit ratio of mass trapping in the right direction. There is a real potential to mass trap (Fountain et al., 2015) or lure and kill ETB and SBW in strawberry crops. Future research should concentrate on trap optimization, ease of use and economics of deploying and maintaining these systems for reducing fruit damage in strawberry crops.

\section{Acknowledgements}

This work was supported by the "Softpest Multitrap" project, funded by FP7-ERA-Net CORE Organic II (project no. 249667) and Hort LINK project HL0184/PC, SF 276 "Pheromone technology for management of capsid pests to reduce pesticide use in horticultural crops" funded by the UK AHDB and Defra. We would like to thank the numerous fruit growers who allowed access to their crops for the trap testing, the numerous technical assistants and students who helped in trap deployment and insect counts.

\section{References}

Aasen, S.S., Trandem, N., 2006. Strawberry blossom weevil Anthonomus rubi Herbst (Col.: Curculionidae): relationships between bud damage, weevil density, insecticide use, and yield. J. Pesticide Sci. 79, 169-174.

Abbes, K., Harbi, A., Chermiti, B., 2012. Comparative study of 2 protection strategies against Tuta absoluta (Meyrick) in late open field tomato crops in Tunisia. EPPO Bull. 42, 297-304.

Bichão, H., Borg-Karlson, A.-K., Araujo, J., Mustaparta, H., 2005a. Five types of olfactory receptor neurons in the strawberry blossom weevil Anthonomus rubi: selective responses to inducible host-plant volatiles. Chem. Senses 30, 153-170.

Bichão, H., Borg-Karlson, A.-K., Wibe, A., Araujo, J., Mustaparta, H., 2005b. Molecular receptive ranges of olfactory receptor neurones responding selectively to terpenoids, aliphatic green leaf volatiles and aromatic compounds, in the strawberry blossom weevil Anthonomus rubi. Chemoecology 15, 211-226.

Blackmer, J.L., Byers, J.A., Rodriguez-Saona, C., 2008. Evaluation of color traps for monitoring Lygus spp.: design, placement, height, time of day, and non-target effects. Crop Prot. 27, 171-181.

Breslow, N.E., Clayton, D.G., 1993. Approximate inference in generalized linear mixed models. J. Am. Stat. Assoc. 88 (421), 9-25.

Cressey, D., 2015. Bee studies stir up pesticide debate. Nature 520, 416.

Croft, B.A., Brown, A.W.A., 1975. Responses of arthropod natural enemies to insecticides. Annu. Rev. Entomology 20, 285-335.

Cross, J., Fountain, M., Hall, D., 2011. Management of European tarnished plant bug in late season strawberries. IOBC/WPRS Bull. 70, 170.

Cross, J.V., Hesketh, H., Jay, C.N., Hall, D.R., Innocenzi, P.J., Farman, D.I., Burgess, C.M., 2006a. Exploiting the aggregation pheromone of strawberry blossom weevil Anthonomus rubi Herbst (Coleoptera: Curculionidae): Part 1. Development of lure and trap. Crop Prot. 25, 144-154.

Cross, J.V., Hall, D.R., Innocenzi, P.J., Hesketh, H., Jay, C.N., Burgess, C.M., 2006b. Exploiting the aggregation pheromone of strawberry blossom weevil Anthonomus rubi (Col.: Curculionidae): Part 2. Pest monitoring and control. Crop Prot. 25, 155-166.

Dembilio, O., Jaques, J.A., 2015. Biology and management of red palm weevil. In: Wakil, W., Faleiro, J.R., Miller, T.A. (Eds.), Sustainable Pest Management in Date Palm: Current Status and Emerging Challenges. Springer, Switzerland, pp. $13-36$.

El-Sayed, A.M., Suckling, D.M., Wearing, C.H., Byers, J.A., 2006. Potential of mass trapping for long-term pest management and eradication of invasive species. J. Econ. Entomology 99, 1550-1564.

European Food Safety Authority, 2015. The 2013 European Union report on pesticide residues in food, 169 EFSA J. 13 (3), 4038. http://dx.doi.org/10.2903/ j.efsa.2015.4038.

Faccoli, M., Stergulc, F., 2008. Damage reduction and performance of mass trapping devices for forest protection against the spruce bark beetle, Ips typographus (Coleoptera Curculionidae Scolytinae). Ann. For. Sci. 65, 309p1-309p9.

Fitzgerald, J., Jay, C., 2011. Chemical control of the European tarnished plant bug, Lygus rugulipennis, on strawberry in the UK. Crop Prot. 30, 1178-1183.

Fountain, M., Cross, J., Jaastad, G., Farman, D., Hall, D., 2010. Developing an effective trap and lure to monitor Lygus rugulipennis. IOBC/wprs Bull. 54, 47-51.

Fountain, M., Cross, J., Jaastad, G., Hall, D., 2008. Some preliminary investigations into the sex pheromones of mirid soft fruit pests. IOBC/WPRS Bull. 39, 33-40.

Fountain, M.T., Jåstad, G., Hall, D., Douglas, P., Farman, D., Cross, J.V., 2014. Further studies on sex pheromones of female Lygus and related bugs: development of effective lures and investigation of species-specificity. J. Chem. Ecol. 40, 71-83. Fountain, M.T. Cross, J.V., Farman, D., Hall, D., 2011. Using pheromones to monitor Lygus populations in fruit crops in the UK. Pheromones other semio-chemicals IOBC/wprs Bull. 72, 7-13.

Fountain, M.T., Shaw, B., Trandem, N., Storberget, S., Baroffio, C., Ralle, B., Rendina, P., Richoz, P., Sigsgaard, L., Borg-Karlson, A.-K., Hall, D., Cross, J.V., Wibe, A., 2015. The potential for mass trapping Lygus rugulipennis and Anthonomus rubi; trap design and efficacy. Integr. Prot. fruit crops Subgr. "Soft Fruits" IOBC-WPRS Bull. 109, 95-97.

Frati, F., Chamberlain, K., Birkett, M., Dufour, S., Mayon, P., Woodcock, C., Wadhams, L., Pickett, J., Salerno, G., Conti, E., Bin, F., 2009. Vicia faba - Lygus rugulipennis interactions: induced plant volatiles and sex pheromone enhancement. J. Chem. Ecol. 35, 201-208.

Haghani, M., Negahban, M., Sedaratian-Jahromi, A., Ghane-Jahromi, M., 2016. Monitoring of an Iranian population of Grapholita funebrana Treitschke, 1835 (Lepidoptera: Tortricidae) using sex pheromone traps: an applicable procedure for sustainable management. Entomofauna 37, 241-252.

Hillocks, R.J., 2012. Farming with fewer pesticides: EU Pesticide Review and resulting challenges for UK agriculture. Crop Prot. 31, 85-93.

Hillocks, R.J., 2013. Impact of EU pesticide reduction strategy and implications for crop protection in the UK and the rest of Europe. Outlooks Pest Manag. 24, 206-209.

Holopainen, J.K., Raiskio, S., Wulff, A., Tiilikkala, K., 2001. Blue sticky traps are more efficient for the monitoring of Lygus rugulipennis (Heteroptera, Miridae) than yellow sticky traps. Agric. Food Sci. Finl. 10, 277-284.

Innocenzi, P.J., Hall, D., Cross, J.V., Hesketh, H., 2005. Attraction of male European tarnished plant bug, Lygus rugulipennis to components of the female sex pheromone in the field. J. Chem. Ecol. 31, 1401-1413.

Innocenzi, P.J., Hall, D.R., Cross, J.V., 2001. Components of male aggregation pheromone of strawberry blossom weevil, Anthonomus rubi Herbst. (Coleoptera: Curculionidae). J. Chem. Ecol. 27, 1203-1218.

Innocenzi, P.J., Hall, D.R., Cross, J.V., Masuh, H., Phythian, S.J., Chittamaru, S., Guarino, S., 2004. Investigation of long-range female sex pheromone of the European tarnished plant bug, Lygus rugulipennis: chemical, electrophysiological, and field studies. J. Chem. Ecol. 30, 1509-1529.

Jay, C., Cross, J., Burgess, C., 2008. Severing damage by Anthonomus rubi populations in the UK. IOBC/WPRS Bull. 39, 131-136.

Koczor, S., Vuts, J., Tóth, M., 2012. Attraction of Lygus rugulipennis and Adelphocoris lineolatus to synthetic floral odour compounds in field experiments in Hungary. J. Pest Sci. 85, 239-245.

Mafra-Neto, A., Habib, M., 2003. Evidence that mass trapping suppresses pink bollworm populations in cotton fields. Entomologia Exp. Appl. 81, 315-323.

Mwatawala, M.W., Mziray, H., Malebo, H., De Meyer, M., 2015. Guiding farmers' choice for an integrated pest management program against the invasive Bactrocera dorsalis Hendel (Diptera: Tephritidae) in mango orchards in Tanzania. Crop Prot. 76, 103-107.

Navarro-Llopis, V., Primo, J., Vacas, S., 2015. Bait station devices can improve mass trapping performance for the control of the Mediterranean fruit fly. Pest Manag. Sci. 71, 923-927.

Oehlschlager, A.C., Chinchilla, C., Castillo, G., Gonzalez, L., 2002. Control of red ring disease by mass trapping of Rhynchophorus palmarum (Coleoptera: Curculionidae). Fla. Entomol. 85, 507-513.

Renkema, J.M., Buitenhuis, R., Hallett, R.H., 2014. Optimizing trap design and trapping protocols for Drosophila suzukii (Diptera: Drosophilidae). J. Econ. Entomology 107, 2107-2118.

Singh, N., Wang, C., Cooper, R., 2013. Effect of trap design, chemical lure, carbon dioxide release rate, and source of carbon dioxide on efficacy of bed bug monitors. J. Econ. Entomology 106, 1802-1811.

Switzer, P.V., Enstrom, P.C., Schoenick, C.A., 2009. Behavioural explanations underlying the lack of trap effectiveness for small-scale management of Japanese beetles. J. Econ. Entomology 102, 934-940.

Teixeira, L.A.F., Mason, K., Isaacs, R., 2009. Control of grape berry moth (Lepidoptera: Tortricidae) in relation to oviposition phenology. J. Econ. Entomology 102, 692-698.

VSN Internation, 2011. GenStat for Windows, fourteenth ed. VSN International, Hemel Hempstead, UK (Web page: GenStat.co.uk).

Walton, V.M., Daane, K.M., Pringle, K.L., 2004. Monitoring Planococcus ficus in South African vineyards with sex pheromone-baited traps. Crop Prot. 23, 1089-1096.

Wibe, A., Borg-Karlson, A.-K., Cross, J., Sigsgaard, L., 2011. Effective trapping of the strawberry blossom weevil. Anthonomus Rubi. IOBC/WPRS Bull. 70, 24.

Wibe, A., Borg-Karlson, A.-K., Cross, J., Bichao, H., Fountain, M., Liblikase, I., Sigsgaard, L., 2014. Combining 1,4-dimethoxybenzene, the major flower volatile of wild strawberry Fragaria vesca, with the aggregation pheromone of the strawberry blossom weevil Anthonomus rubi improves attraction. Crop Prot. 64, $122-128$.

Witzgall, P., Kirsch, P., Cork, A., 2010. Sex pheromones and their impact on pest management. J. Chem. Ecol. 36, 80-100. 